\title{
MULHERES GRIÔS QUILOMBOLAS: UM ESTUDO INICIAL SOBRE IDENTIDADE DE GÊNERO E IDENTIDADE ÉTNICA
}

\author{
Adriana Cardoso Sampaio ${ }^{1}$ \\ Ana Cláudia Lemos Pacheco ${ }^{2}$
}

\begin{abstract}
Resumo: O presente artigo buscou pesquisar em bases científicas e teóricas o que tem sido produzido sobre mulheres quilombolas e seu pertencimento étnico-racial e identidade de gênero. Os resultados encontrados neste estudo inicial revelam que pouco tem se investigado e produzido cientificamente sobre mulheres negras quilombolas, apontando para a urgência em conhecer e visibilizar as histórias de vida dessas mulheres e sua importância na constituição identitária e sociocultural da comunidade a qual fazem parte.

Palavras-chave: Mulheres Quilombolas, Identidades, Gênero, Etnicidade, Raça.
\end{abstract}

\section{QUILOMBOLAS GRIOTS WOMEN: A STUDY ON INITIAL GENDER IDENTITY AND ETHNIC IDENTITY}

\begin{abstract}
This paper aims to research on scientific and theoretical bases which have been produced on maroon women and their ethnic-racial belonging and gender identity. The results of this initial study show that little has been investigated and scientifically produced on maroon black women, pointing to the urgent need to understand and visualize the life stories of these women and their importance in the socio-cultural identity and constitution of the community to which they belong.

Keywords: Quilombola Women, Identities, Gender, Ethnicity, Race.
\end{abstract}

\section{Introdução}

Das várias comunidades quilombolas reconhecidas no Brasil, em boa parte delas, a presença das mulheres Griôs é de grande relevância na organização comunitária, na sustentação familiar e na transmissão da história e cultura africanas, afro-brasileiras e indígenas. O termo Griô aqui utilizado parte de nosso interesse em buscar agentes da tradição oral presentes no Quilombo do Barro Preto localizado na cidade de Jequié, Bahia.

1 Licenciada em Pedagogia (UESB), Pós-graduada em Gestão Educacional - (UESB) e mestranda em Relações Étnicas e Contemporaneidade (UESB). Atuou como coordenadora pedagógica em escolas municipais dos municípios de Brejões (BA) e Planaltino (BA). E-mail: adrianacsampaio@hotmail.com.

2 Profa. Dra. Adjunta de Sociologia da Universidade do Estado da Bahia, Campus- I, Salvador, Bahia e Professora permanente do Programa de Mestrado em Relações Étnicas e Contemporaneidade, da Linha 2: Etnias, Gênero e Diversidade Sexual do ODEERE| UESB. Líder do Grupo de Pesquisa Candaces: gênero, raça, cultura \& sociedade, da UNEB, certificado pelo CNPq. E-Mail: ana_pachecau@hotmail.com. 
A palavra Griô, também chamado dieli em bambara; nyamakala em fulfulde significa animadores públicos na cultura africana e se tornou mais conhecido pelo termo francês griot. Os Griots eram definidos como mestres e portadores de sabedoria. Na cultura africana, eram conhecidos como trovadores ou menestréis classificados como griots músicos (tocam instrumentos, cantam e compõem); griots embaixadores e cortesãos (responsáveis por mediar desavenças entre famílias) e griots genealogistas, historiadores e poetas (contadores de histórias e grandes viajantes) (HAMPATÉ BÂ, 2010, p. 191-193). Os Griôs ocuparam as funções de preservar a história e repassá-las a outras gerações por meio do conhecimento de genealogias de famílias, mitos, histórias, costumes e culturas antigas das regiões e locais onde nasciam e residiam (LIMA; COSTA, 2015, p. 229, 237).

No Brasil, a apropriação brasileira do griot africano se dá em um contexto de recriação e reelaboração de práticas africanas diante do processo de colonização e diáspora vivenciado pela população africana traficada como escrava e pela população indígena presentes em nosso país. Para Lílian Pacheco e Márcio Caires, que através do Grãos de Luz e Griô e outras entidades vêm mobilizando a criação de redes nacionais de cultura com o intuito de valorizar os saberes e as/os agentes da tradição oral, o termo Griô, que seria uma apropriação do griot africano, é um termo apropriado para identificar as rendeiras, as mães e pais-de-santo, as reiseiras, os mestres de capoeira, os mestres de samba-de-roda, as rezadeiras e curadores, as parteiras e muitos outros personagens como representantes da sabedoria da tradição oral e referência de ancestralidade, identidade e cultura no Brasil (LIMA; COSTA, 2015, p. 229 e p. 237).

Cientes da grande importância das mestras Griôs, nossa proposta nesse artigo é investigar o campo de estudos sobre as mulheres quilombolas com o objetivo de dar visibilidade às pesquisas realizadas sobre esse tema na Bahia e no Brasil. Ao fazermos o levantamento do tema, nos deparamos com uma lacuna em relação às mulheres negras quilombolas de comunidades rurais e urbanas. Estas últimas têm uma composição multiétnica, o que constitui a princípio uma singularidade a ser investigada, diferentemente de outros quilombos estudados, cuja concentração de pessoas negras, descendentes de africanos, é maior, como ocorre na maioria dos quilombos rurais, presentes, por exemplo, nas pesquisas realizadas por Silva (2000) e Santos (2012). Sendo assim, o nosso interesse é entender a produção das identidades étnico-raciais e de gênero de mulheres quilombolas mais velhas na constituição da comunidade quilombola do Barro Preto, localizada, na zona urbana da cidade de Jequié, Bahia. 
A partir da realização do estado do conhecimento, utilizou-se como filtros mulheres Griôs e mulheres e identidade étnica em bancos de pesquisas como revistas e anais de eventos, porém nenhum resultado foi encontrado. Já com o filtro mulheres quilombolas foi possível encontrar algumas investigações como resumos de teses de mestrado e doutorado na base de dados da CAPES (Coordenação de Aperfeiçoamento de Pessoal de Nível Superior): entre os anos de 2011 e 2012 vinte e uma pesquisas foram realizadas. Dessas, apenas quatro dissertações tinham como tema mulheres quilombolas discutindo: trajetória educacional; identidades e territórios; histórias femininas, poder e resistência; fala e papel da mulher na comunidade quilombola.

Com os resultados encontrados foi possível perceber como a mulher negra quilombola ainda continua invisibilizada no espaço acadêmico e científico, o que no leva a indagar sobre as discussões acerca das categorias gênero, etnia e raça nas produções científicas, dados que apontam a importância de investigar mulheres negras, mulheres quilombolas e, principalmente, mulheres Griôs, e a necessidade de conhecer, visibilizar e valorizar as histórias de vida dessas mulheres em seu protagonismos de luta, empoderamento e participação na história e constituição identitária e sociocultural dos espaços em que participam.

Boa parte dos estudos sobre quilombos no Brasil e na Bahia não analisaram a presença das mulheres do ponto de vista de sua importância histórica, econômica e cultural na organização social e política das comunidades quilombolas. Segundo algumas estudiosas do campo de estudos de gênero e raça isso ocorre devido a pouca importância que a produção do conhecimento acadêmico atribui às discussões de gênero, enquanto uma categoria analítica importante para se entender as relações de dominação interseccionadas por outras categorias, tais como: raça/etnia, classe, geração, sexualidade. Esta invisibilidade tem contribuído para a negação das mulheres negras enquanto sujeitos históricos na formação do Brasil devido aos fundamentos ideológicos do patriarcado e do racismo, colocando a mulher negra numa posição de subalternidade, de discriminação e de violência, tanto psicoemocional quanto física. Em face dessa subvalorização,

[...] é válida a afirmação de que o racismo rebaixa o status dos gêneros. Ao fazê-lo, institui como primeiro degrau de equalização social a igualdade intragênero, tendo como parâmetro os padrões de realização social alcançados pelos gêneros racialmente dominantes. Por isso, para as mulheres negras atingirem os mesmos níveis de desigualdades existentes entre homens e mulheres brancos significaria experimentar uma extraordinária mobilidade social, uma vez que os homens negros, na maioria dos indicadores sociais, encontram-se abaixo das mulheres brancas (CARNEIRO, 2003, p. 119. Grifo da autora). 
Identificar pesquisas, mesmo que em pequeno número, investigando mulheres quilombolas, demonstram avanços animadores. Uma delas, realizada por Maria José dos Santos, na Comunidade Quilombola das Onze Negras do Cabo de Santo Agostinho (PE), que trata sobre as trajetórias educacionais de mulheres quilombolas e revela dados importantes. Santos (2012) aponta em sua pesquisa que as características de organização desta comunidade mostram alguns diferenciais, "pois são lideradas por mulheres, [...] o repasse das lideranças acontecem de geração em geração, com um elo familiar ou de convivências no Quilombo, mostrando o fortalecimento e a resistência da continuidade da luta pelo coletivo" (SANTOS, 2012, p. 38). Logo se percebe que este campo de pesquisa é de extrema relevância, pois apontam espaços onde mulheres negras têm-se constituído como referências em seus grupos étnicos por meio de suas histórias de vida.

\section{Mulheres e quilombos no Brasil}

Atualmente existem muitas comunidades de remanescentes quilombolas reconhecidas no Brasil e em boa parte delas a presença das mulheres é de grande relevância exercendo papéis no sustento de famílias, preservando e transmitindo a história e cultura africanas e afrobrasileiras para as novas gerações e buscando melhor qualidade de vida para sua comunidade. Nesta, se constrói e reproduz diversos valores que funcionam como referência sociocultural no comportamento das pessoas e nos meios de produção do trabalho. Ao mesmo tempo em que o grupo pode fortificar ideias que contribuam na valorização do pertencimento étnicoracial por meio de um consciente coletivo de suas origens, heranças, costumes, crenças e da necessidade de buscar melhor qualidade de vida, ele também pode reproduzir o preconceito e intensificar a discriminação, aumentando assim a desvalorização de própria identidade do grupo.

Mesmo com o enfrentamento histórico da escravidão, da violência e do extermínio, a população negra no Brasil, por meio de seus valores ancestrais, crenças religiosas, da cultura oral e saberes que lhes permitiam se identificar como grupos étnicos (BARTH, 1969, p. 189190), buscaram nos quilombos uma das primeiras formas de resistência e luta pela sobrevivência e uma vida comunitária, digna e livre (FIABANI, 2012). De origem bantu, a palavra "quilombo" significa acampamento guerreiro na floresta (LEITE, 2008, p. 965). Os quilombos eram constituídos majoritariamente de pessoas negras que sobreviviam como escravas nas 
casas e fazendas de seus compradores e lá se refugiavam para viver em liberdade e coletivamente. A organização política dos quilombos sustentava uma economia familiar comunitária e de subsistência, onde tudo que era produzido em excedente era para uso de todos; era comum a existência de famílias poliândricas (uma mulher se relaciona com mais homens de uma mesma aldeia) pelo fato do número de mulheres ser pequeno nos quilombos; e tinham como lideranças um chefe e um grupo de conselheiros responsáveis pelas tomadas de decisão em comum acordo (GENNARI, 2011, p. 37-38).

Durante muito tempo, os quilombos foi um assunto tratado como algo pertencente ao tempo da colonização brasileira, logo, considerada extinguida em nossa atualidade. Esta visão histórica sobre quilombos dificulta o reconhecimento destes grupos étnicos, bem como sua valorização e respeito à legalidade de seus direitos "à identificação, o reconhecimento, a delimitação, a demarcação e a titulação da propriedade definitiva das terras ocupadas por remanescentes dos quilombos", regulamentados desde o decreto $\mathrm{n}^{\circ} 4.887 / 03$ de acordo ao disposto no artigo 68 do Ato das Disposições Constitucionais Transitórias (BRASIL, 2003).

Dos muitos aspectos que constituem um quilombo em recentes pesquisas étnicas, queremos chamar a atenção para alguns apontados por Silva (2000, p. 5):

[...] ao contrário do que estudiosos do tema costumavam afirmar, as comunidades negras rurais não são grupos que se isolaram da sociedade envolvente. Outro aspecto comum é que os laços de parentesco, consangüíneos ou por afinidade, são a base da organização social. Finalmente, as histórias desses grupos, majoritariamente negros, são reconstruídas a partir de narrativas orais (SILVA, 2000, p. 5).

Diante disto, não é mais possível identificar quilombos como algo ligado a "negro fugido", "guerra de negros no mato" ou a grupos extintos no tempo da colonização. As comunidades quilombolas contemporâneas estão muito mais próximas da definição de grupos étnicos (BARTH, 1969) compostos por mais de uma etnia, que se autodefinem a partir de aspectos comuns como as relações com a terra ou o território urbano, o parentesco, a ancestralidade, as tradições e as práticas culturais próprias, engendrados em torno de bases políticas autoorganizadas, ou seja, "cada quilombo tem uma experiência particular de formação, em que os mencionados fatores, e outros, foram com certeza, avaliados pelos que desejavam se aquilombar" (SILVA, 2000, p. 12-13).

Sempre ocupando a função de preservar a história e repassá-las a outras gerações por meio do conhecimento de genealogias de famílias, mitos, histórias, costumes e culturas antigas das regiões e locais onde nasciam e residiam, os/as Griôs transformaram-se em referência 
de tradição, identidade e cultura no Brasil. Todavia, muitas dessas sábias mulheres permanecem invisíveis, marcadas pela discriminação de gênero, raça e classe, que tem seus fundamentos nas ideologias do patriarcado e do racismo, colocando a mulher numa posição de subalternidade, de discriminação e de violência, tanto psicoemocional quanto física.

Durante muito tempo, o gênero foi compreendido como o sexo das pessoas, um código biológico recebido desde o momento do nascimento para diferenciar mulher e homem. Mais recentemente, "as feministas começaram a usar a palavra "gênero" mais seriamente, no sentido mais literal, como uma maneira de referir-se à organização social da relação entre os sexos" (SCOTT, 1989, p. 2), como uma construção identitária realizada de forma individual em interação com a sociedade e a cultura. Assim como as formas de expressão dos desejos e prazeres, as identidades de gênero e sexual são compostas, definidas e moldadas pelas redes de poder das relações sociais (LOURO, 2007, p. 11). Suely Kofes (1992), analisando esta mesma categoria, complementa sobre o olhar de Scott e dialoga com Louro (2007):

\footnotetext{
Gênero seria o conhecimento sobre a diferença sexual. Conhecimento entendido como: sempre relativo; produzido por meios complexos, isto é, por amplos e complexos quadros epistêmicos e referindo-se não apenas às idéias, mas também às instituições e estruturas, práticas cotidianas, rituais, enfim tudo aquilo que constituiria as relações sociais (KOFES, 1992, p. 21).
}

Os valores e conceitos apreendidos durante o desenvolvimento psico-afetivo-social estão norteados por discursos ideológicos que servem de modelo-padrão a ser seguido para diferenciar o ser mulher do ser homem. O que na maior parte das vezes se encontra oculto por detrás dessas diferenciações é o objetivo de empoderar um gênero, negligenciando os direitos do outro, "historicamente caracterizadas por uma situação de subordinação das mulheres" (SARDENBERG; MACEDO, 2011, p. 1).

Quando analisamos a realidade histórica de mulheres negras, a discriminação e estado de submissão se tornam muito mais abrangentes. Marcadas pelas ideologias do patriarcado e do racismo, contexto ligado à história da formação do Brasil, a mulher negra encontra-se numa posição de subalternidade, de discriminação, de violência e vulnerabilidade, tanto psicoemocional quanto física, bem mais preocupante, como demonstra os indicadores do Instituto de Pesquisa Econômica Aplicada (IPEA) e o então Fundo de Desenvolvimento das Nações Unidas para a Mulher (UNIFEM), hoje ONU Mulheres (DOSSIÊ MULHERES NEGRAS, 2013) e afirma Spivaki (2010): 
dade (e por isso) [...] participar do trabalho antissexista entre as mulheres de cor ou as mulheres sob a opressão de classe no Primeiro ou no Terceiro Mundo está inegavelmente na ordem do dia (SPIVAK, 2010, p. 67,86).

As mulheres negras, principalmente das classes menos favorecidas, encontram-se em situações de violência, como da ausência de empoderamento de decidir sobre seus corpos, "a violência simbólica da mídia, dos livros escolares, da linguagem, a violência médica, sexual, psicológica, de assédio moral no trabalho, etc., enfim a violência nas relações familiares" (BLAY, 2005, p. 1. Grifos da autora). São discriminações presentes de forma tão ocultas no cotidiano que muitas vezes são invisíveis às mulheres negras, de modo que as tornam ainda mais vulneráveis à exploração, auxiliando assim na legitimação de ideias sexistas e racistas. Por isso, é crucial que os estudos de gênero e raça sejam elaborados levando em consideração o conceito de interseccionalidade, como afirma Kimberlé Crenshaw (2002):

\begin{abstract}
A associação de sistemas múltiplos de subordinação tem sido descrita de vários modos: discriminação composta, cargas múltiplas, ou como dupla ou tripla discriminação. A interseccionalidade é uma conceituação do problema que busca capturar as conseqüências estruturais e dinâmicas da interação entre dois ou mais eixos da subordinação. Ela trata especificamente da forma pela qual o racismo, o patriarcalismo, a opressão de classe e outros sistemas discriminatórios criam desigualdades básicas que estruturam as posições relativas de mulheres, raças, etnias, classes e outras. Além disso, a interseccionalidade trata da forma como ações e políticas específicas geram opressões que fluem ao longo de tais eixos, constituindo aspectos dinâmicos ou ativos do desempoderamento (CRENSHAW, 2002, p. 177).
\end{abstract}

Nesse sentido é de grande importância a interseccionalidade nos estudos de gênero e raça, para que se construa uma análise profunda e real acerca da discriminação vivida por mulheres negras na sociedade, pois assim como é real o fato de que todas as mulheres estão sujeitas ao peso da discriminação, de alguma forma, "também é verdade que outros fatores relacionados à suas identidades sociais, tais como classe, casta, raça, cor, etnia, geração, religião, origem nacional e orientação sexual" (CRENSHAW, 2002, p. 173), acentuam as diferenças que influenciam diferentemente na forma como vários grupos de mulheres vivenciam a discriminação.

Em nossa contemporaneidade, a mulher negra vem realizando conquistas em diversos espaços sociais, movidas principalmente pela participação social em movimentos e organizações políticas, pelos estudos feministas e estudos de gênero. Estudiosas negras como Gonzalez (1980), Collins (1989), Bairros (1995); hooks (1995), Pacheco (2013), Moreira (2011) dentre outras, afirmam a grande relevância dos estudos de gênero e raça realizados a partir de um novo ponto de vista - por e com mulheres negras, pois o lugar em que nos situamos nos auxilia determinar uma melhor interpretação "sobre o duplo fenômeno do racismo e do se- 
xismo, que constitui a sintomática que caracteriza a neurose cultural brasileira. Nesse sentido, veremos que sua articulação com o sexismo produz efeitos violentos sobre a mulher negra em particular" (GONZALEZ, 1980, p. 224).

Abrir espaço para o pensamento negro feminino também se torna essencial na medida em que retira a mulher negra da posição de subalternidade e invisibilidade para a posição de protagonistas e produtoras, seja de conhecimento teórico, científico ou prático nas diversas atuações profissionais, acadêmicas, culturais e sociais que a mulher negra tem assumido atualmente e na história.

A neurose da cultura brasileira, como afirma Gonzalez (1980, p. 235), busca ocultar e inferiorizar a mulher negra na história da constituição do Brasil, mas ao mesmo tempo não percebe que ela está presente de maneira unânime em seu eixo nuclear — na tão sagrada instituição familiar (e, logo, na gênese da nação brasileira), onde o homem branco, na figura latente do patriarcado, na realidade, tinha relações sexuais com a mucama, tinha como mãe de seus filhos a mãe preta e tinha a mulher branca para efetivar as aparências culturais sustentadoras das relações socioeconômicas, tão necessárias no engendramento do país.

Discutir, então, a identidade da mulher negra é fazer emergir provocações, tensões, contradições e possíveis alternativas de desconstrução dos estereótipos inculcados pelo sexismo e racismo que vem perpetuando uma iconografia de representação cultural coletiva de que a mulher negra está socialmente para servir aos outros, desde a escravidão aos dias atuais, vista como símbolo "quintessencial” de uma presença feminina próxima da visão natural, animalesca e primitiva (hooks, 1995, p. 5).

\section{Mulheres quilombolas: primeiros dados etnográficos}

Em nosso objetivo de pesquisa, a mulher negra na comunidade quilombola, especialmente, as idosas, torna-se referência de valores e saberes, de ancestralidade, de signos e identidade, tanto étnica quanto de gênero, sexual, de classe, política e cultural para a família e para o grupo dos quais participam. Por isso, buscar compreender como tem se constituído o pertencimento étnico-racial e a identidade de gênero de mulheres Griôs da Comunidade Quilombola do Barro Preto, em Jequié, Bahia, possivelmente nos possibilitará uma reflexão acerca da construção das identidades étnica, raciais e de gênero da comunidade estudada. 
A escolha por pesquisar as histórias de vida de mulheres mais velhas do Barro Preto tem relevância social por serem mulheres que vivem na comunidade há muitos anos, e por meio de suas histórias de vida acreditamos que poderão ser documentados "artefatos culturais" (GEERTZ, 2012, p. 59), ou seja, informações importantes sobre suas identidades e práticas tradicionais e ainda sobre a formação do próprio quilombo; documentos estes que podem ser de grande relevância para comunidade em seu processo contínuo de construção identitária e reconhecimento social, cultural, legal e político.

Fazer etnografia, então, é realizar uma observação e descrição intensa do espaço pesquisado, levando em consideração a complexidade da cultura e das variadas relações de convivência ali articuladas. Desta forma, segundo Geertz (2012), a cultura precisa ser compreendida segundo dois aspectos cruciais.

A cultura é vista melhor não como um complexo de padrões concretos de comportamento - costumes, usos, tradições, feixes de hábitos - como tem sido o caso até agora, mas como um conjunto de mecanismos de controle - planos, receitas, regras, instruções (o que os engenheiros da computação chamam de "programas") para governar o comportamento. [...] Outro aspecto é de que o homem é precisamente o animal mais desesperadamente dependente de tais mecanismos de controle, extragenéticos, fora da pele, de tais programas culturais, para ordenar seu comportamento (GEERTZ, 2012, p. 33. Grifo meu).

Sendo assim, por meio da etnografia intentamos compreender as pessoas, suas múltiplas identidades e a formas como se relacionam e atuam na sociedade, sem perder de vista que mais importante do que compreender sobre o "status do ser (ontológico) é questionar qual é a sua importância" (GEERTZ, 2012, p. 8), ou seja, o que é transmitido, produzido, reproduzido e ressignificado pelos sujeitos envolvidos pela via da cultura.

Tendo em vista que nossa proposta de estudo se dá dentro de um quilombo urbano, realizar etnografia neste espaço possibilita à/ao agente da pesquisa evitar dicotomias na interpretação do cenário das regiões urbanas contemporâneas, a partir de "uma perspectiva capaz de apreender os padrões de comportamento, não de indivíduos atomizados, mas dos múltiplos, variados e heterogêneos conjuntos de atores sociais" (MAGNANI, 2002, p. 17), cuja vida cotidiana acontece nas cidades; numa perspectiva de perto e de dentro, que parte do total para o particular e do particular para o total sem perder de vista as particularidades e singularidades nem o que é totalizante - uma perspectiva dialética.

Desse modo, as nossas primeiras observações etnográficas na comunidade quilombola estudada nos possibilitou registrar alguns aspectos dessa perspectiva de "perto" e de " dentro" 
desse conjunto de identidades. São relatos, ainda escassos, nesse momento da nossa pesquisa, mas que nos revelam um pouco das percepções e vivências de algumas mulheres griôs (idosas) em relação à cultura local.

\section{Aspectos etnográficos da pesquisa de campo}

Comunidade Quilombola do Barro Preto, Jequié, Bahia, 06.10.15.

Casa de Dona Adélia — a bordadeira

Dona Adélia é bordadeira e costureira: borda fuxicos, toalha, colchas de retalho, panos de prato e artigos como bolsa e bonecas. Costurou muitas roupas para diversas pessoas - ciganas, pessoas do terreiro, mulheres e homens de vários lugares da cidade - durante anos aqui no Barro Preto de onde tirava seu sustento.

Em uma das minhas visitas à casa de Dona Adélia, a encontrei sentada na sua máquina de costura na cozinha de sua casa. Dona Adélia tem pele branca, cabelo liso e branco, um corpo rechonchudo e já está com mais de 80 anos. Estava vestida com um vestido de tecido simples e folgado, bem confortável e usava seus óculos de grau. Ela trazia um sorriso acolhedor e olhos de menina esperta. Enquanto costurava, bastante concentrada, uma barra de uma colcha para sua filha (que foi uma de minhas professoras em tempos de escola), Dona Adélia me contava um pouco de sua vida.

Perguntei como ela começou a costurar. Ela então contou que sua mãe costurava e cozinhava muito bem. Que quando moravam na fazenda, na região de Jaguaquara (município vizinho de Jequié), onde nasceu, um homem chamado "Tatu” tinha encomendado uma calça a sua mãe. E como ela sempre olhava sua mãe, tinha muita vontade de costurar.

\section{"Pensei: minha mãe já chega tão cansada, vou fazer essa calça!"}

Então pegou o corte de pano e pôs em cima de uma mesa, pegou uma calça de seu pai e foi medindo e cortando o tecido. Pediu ao pai pra colocar a linha máquina de costura pra ela costurar a calça. O pai ficou surpreso. 
Então começou a costurar a calça com muito cuidado e com medo de errar e sua mãe brigar com ela. Mas por fim tudo deu certo. Ela fez a calça e colocou no mesmo lugar que estava o tecido antes de sua mãe chegar.

Quando sua mãe chegou e olhou a calça perguntou o que era e disse que estava ótima e bem infestada (pregueada). Deste dia em diante ela costurava e bordava tudo que via: roupas, rendas, ponto-cruz, vagonite, fuxico e retalhos.

Dona Adélia disse que sua mãe nunca tinha parado pra lhe ensinar, mas ela aprendeu olhando. E com o que aprendeu sustentou sua família, a qual ela mantinha financeiramente mais que seu esposo.

Dona Adélia contou outro caso: quando menina ia lavar roupa no riacho com sua mãe. Ela lavava sua própria roupa e mais uma trouxa de roupas de bonecas "que naquela época tinha muitas bonecas". Um dia, lavando roupas, viu um vestido roa de cetim que lhe chamou atenção. Era de uma família da região com mais condição. Ela disse que achou o modelo do vestido lindo e mostrou a sua mãe. Ao chegar em casa, o vestido não lhe saia do pensamento, então ela pegou um retalho de tecido e tentou fazer um vestido de boneca do mesmo modelo.

"E não é que eu consegui, Adriana?!"

Então correu e mostrou à mãe:

“Olha mãe o vestido que a gente viu? Não tá igual?”

E a mãe ficou surpresa! E com o mesmo vestido da boneca Fez um igual para Dona Adélia e para outras mulheres da região e assim foi aumentando a sua freguesia.

Don Adélia relatou que sofreu muito quando era jovem e suas filhas ainda pequenas para sustentar sua família. Que também passou dificuldades com seu esposo dentro de casa, mas pediu que não escrevesse nada sobre este assunto na pesquisa. Disse ainda que tudo que ela lutou hoje ela espera ser "mais valorizada pela família". 
Comunidade Quilombola do Barro Preto, Jequié, Bahia, 13.11.15

Casa de Mãe Nininha — as mulheres do terreiro

Eu e meu companheiro fomos visitar Dona Betinha e Mãe Nininha, sua mãe. Elas moram no Alto da Bela Vista, bairro ao lado do Barro Preto. Dona Betinha é filha única (de sangue) de Mãe Nininha, que é mãe-de-santo e já está com 96 anos de idade.

Conheci Dona Betinha no caruru de Dona Tide, uma senhora aqui do Barro Preto que mantém a tradição do caruru. E nesta visita fui saber se sua mãe estava melhor de saúde e convidar Dona Betinha para participar da pesquisa.

Ao chegar, encontramos Dona Betinha sentada na porta da casa, descansando depois de comer jaca. Uma senhora alta, de pele bastante escura, magra, vestida de roupa simples. Nos recebeu com muita atenção e nos convidou pra entrar e sentar. Ficamos na sala enquanto Mãe Nininha terminava de comer jaca também.

A casa de Mãe Nininha é bastante comprida e com muitos cômodos. Com uma mobília bastante simples, móveis e objetos típicos de nossa região. Me chamou atenção um pote de água feito de barro em uma das salas da casa e mais ao fundo o salão onde acontece as festas e rituais do terreiro. Foi neste salão que aconteceu algumas semanas antes o caruru que participei, onde tinha uma mesa com 21 crianças, Cosme e Damião e Santa Bárbara, muitos doces, flores, brinquedos e a presença de muitos Erês incorporados. Depois de levantar a mesa, Dona Betinha me chamou pra conhecer o quarto dos santos, de uma riqueza ancestral africana, brasileira imensa e bastante sincrética.

Dona Betinha nos contou que nasceu em Jequié e que depois foram morar em Itagi, cidade próxima a Jequié. Depois voltaram pra Jequié e moraram em bairros vizinho ao Barro Preto (Caixa d'água, Alto do Cruzeiro) e agora moram no Alto da Bela Vista.

Nos contou que Mãe Nininha foi filha-de-santo de Antônio Borokô e ela de sua própria mãe.

Com a idade avançada de Mãe Nininha, Dona Betinha vive com sua mãe para lhe cuidar, mas não o faz sozinha: ela conta com a ajuda de muitas filhas adotivas e filhos-de-santo de sua mãe. 
Segundo moradoras/es do bairro, Mãe Nininha foi uma mulher que ajudou muita gente: ajudou a construir casas, adotou crianças. Hoje, com a idade avançada e algumas doenças, Mãe Nininha sente dificuldade para ouvir, enxergar e andar. Ainda assim, continua dirigindo seu terreiro com a ajuda de suas filhas e filhos.

Enquanto conversávamos sobre estas coisas, chegou na casa de Mãe Nininha Dona Maria Xangô, outra Griô que também penso em convidar para participar da pesquisa. Aproveitei e perguntei a ela se era rezadeira como algumas moradoras tinham me dito e ela me confirmou dizendo que aprendeu com sua mãe. Logo depois contou um pouco sobre esta prática como nomes específicos que se dá às folhas usadas pra rezar e as formas de usá-las: umas pra rezar, outras pra banhar e outras pra chá.

No meio da conversa Mãe Nininha pediu pra Dona Maria Xangô lhe rezar, pois estava sentindo um incômodo nos olhos e não a deixava dormir de noite. Então Dona Maria Xangô foi até o Pé de Quarana no beco da casa de Mãe Nininha pegar uns galhos de folha. Como as folhas estavam no alto, ela me pediu pra pegar três ramos de folhas. Ela disse que não se pode usar folhas de árvores de rua para rezar e só se reza com a luz do sol: "depois que o sol se põe não deve se rezar".

Então Dona Maria Xangô rezou Mãe Nininha, sua mãe-de-santo, em nossa presença. Foi uma das mais belas imagens que já vi. Entre as palavras proferidas escutei o pai-nosso, a salve-rainha e outra oração específica que não sei completamente, mas já tinha escutado através de meu avô que também era rezador.

Dona Dadá também chegou na casa e se sentou pra prosar conosco. Ela é filha adotiva de Mãe Nininha.

Na sala da casa havia uma homenagem do Movimento Negro Mocambo Odara à Mãe Nininha por ser referência de cultura afro-brasileira no Barro Preto e em Jequié.

Antes de sairmos, Dona Betinha confirmou participar de minha pesquisa. Ao sair da casa, Mãe Nininha me deu sua benção e disse: "Oxalá te abençoe minha filha".

Voltamos pra casa junto com Dona Maria Xangô. No caminho, ela nos contou que também andou no trem de ferro que passava pelo Barro Preto. Fiquei de lhe fazer uma visita e o convite para participar da pesquisa. 


\section{Considerações finais}

O estudo inicial sobre a identidade étnica e de gênero de mulheres Griôs na comunidade de remanescentes quilombolas do Barro Preto apresenta informações relevantes sobre as mulheres mais velhas que tem sustentado a prática de tradição oral por meio de suas histórias de vida. A partir dos primeiros registros documentados no diário de campo já é possível identificar uma riqueza de elementos que constituem suas identidades de gênero e étnica através de suas vivências como mulheres trabalhadoras, autônomas, que sustentaram e ainda ajudam a sustentar seus lares a partir dos saberes aprendidos por meio da tradição oral, como o bordado e a costura e a religiosidade do candomblé, exercidos, vivenciados e ensinados por suas/seus ancestrais, possivelmente de origem africana e europeia.

A forma de olhar, de falar, de receber as/os visitantes em seus lares, de convidar para participarem de suas vivências; o orgulho, alegria e o sabor com que contam de suas trajetórias; os objetos e símbolos presentes em suas casas e seus corpos demonstram a presença de seus ancestrais, suas crenças, costumes e culturas que alicerçaram seus saberes e práticas.

Essas primeiras informações, ainda que rasas, nos possibilitam uma reflexão acerca da construção das identidades étnicas e de gênero de mulheres mais velhas presentes no Quilombo do Barro Preto, dados que podem contribuir em dar visibilidade aos novos espaços alternativos de sensibilização que contribuam na luta contra o preconceito e a discriminação da mulher e dos povos quilombolas, bem como na valorização das agentes de tradição oral como referência identitária étnica e de gênero.

\section{Referências}

BAIRROS, Luiza. Nossos feminismos revisitados. Revista Estudos Feministas, v. 3, n. 2, 1995.

BARTH, Fredrik. Grupos étnicos e suas fronteiras. The social organization of culture difference.Bergen, Oslo: Universitteraforlaget, 1969 In POUTIGNAT, Philippe; STREIFFFERNART, Jocelyne. Teorias da etnicidade: seguido de grupos étnicos e suas fronteiras de Fredrik Barth. Trad. Elcio Fernandes. 2. ed. São Paulo: Ed. Unesp, 2011.

BLAY, Eva Alterman. A violência de gênero no âmbito familiar e suas repercussões na relação de trabalho. I Congresso Internacional Sobre Mulher, Gênero e Relações de Trabalho. 
Goiânia: 2005. Disponível em:

http://nemgeusp.weebly.com/uploads/6/1/5/7/6157532/violencia_genero_blay.pdf. Acesso em 22.10.2014.

BRASIL, Presidência da República. Decreto $n^{\circ} 4.887 / 03$. Casa Civil. Subchefia para Assuntos Jurídicos. Brasília: 2003. Disponível em:

www.planalto.gov.br/ccivil_03/decreto/2003/d4887.htm. Acesso em 18.06.2015.

CARNEIRO, SUELY. Mulheres em movimento. Estudos avançados, n. 17 (49), 2003. Disponível em: http://www.scielo.br/scielo.php?pid=S0103-

40142003000300008\&script=sci_arttext. Acessado em: 25.05.2105.

COLLINS, Patricia Hill. The Social Construction of Black Feminist Thought. Signs, v. 14, n. 4, Common Grounds and Crossroads: Race, Ethnicity, and Class in Women's. Lives. (Summer, 1989), p. 745-773. Disponível em:

https://diversedynamics.files.wordpress.com/2007/01/collins.pdf. Acesso em: 04.07.15.

CRENSHAW, Kimberlé. Documento para o encontro de especialistas em aspectos da discriminação racial relativos ao gênero. Revista Estudos Feministas, n. 1. 2002.

DOSSIE MULHERES NEGRAS. Retrato das condições de vida das mulheres negras no Brasil. Organizadoras: Mariana Mazzini Marcondes [et al.]. Brasília: Ipea, 2013.

FIABANI, Adelmir. Mato, Palhoça e Pilão: o quilombo, da escravidão às comunidades remanescentes. 2. ed. São Paulo: Expressão Popular, 2012.

GEERTZ, Clifford. A interpretação das culturas. Rio de Janeiro: LTC, 2012.

GENNARI, Emilio. Em busca da Liberdade: traços das lutas escravas no Brasil. 2. ed. São Paulo: Expressão Popular, 2011.

GONZALES, Lélia. Racismo e sexismo na cultura brasileira. IV Encontro Anual da Associação Brasileira de Pós-graduação e Pesquisa nas Ciências Sociais. Rio de Janeiro: outubro 1980.

HAMPATÉ BÂ, A. A tradição viva In: HISTÓRIA GERAL DA ÁFRICA, I. Metodologia e pré-história da África / editado por Joseph Ki-Zerbo. 2.ed. rev. Brasília: UNESCO, 2010.

hooks, bell. Intelectuais negras. Estudos Feministas, v. 3, n. 2, 1995. Disponível em: https://periodicos.ufsc.br/index.php/ref/article/view/16465/15035. Acesso em 20.10.2014.

KOFES, Maria Suely. Categorias analítica e empírica: gênero e mulher — disjunções, conjunções e mediações. XVIII Reunião da Associação Brasileira de Antropologia (ABA). Belo Horizonte, abril 1992.

LEITE, Ilka, Boaventura. O projeto político quilombola: desafios, conquistas e impasses atuais. Revista Estudos Feministas. Florianópolis, 16(3): 424, set./dez. 2008.

LIMA, Mestre Alcides de; COSTA, Ana Carolina Francischette da. Dos griots aos Griôs: a importância da oralidade para as tradições de matrizes africanas e indígenas no Brasil. Dossiês Pedagogia Griô. Revista Diversitas. São Paulo, ano 2, n. 3. set. 2014/mar. 2015. 
LOURO, Guacira Lopes (Org.). Pedagogias da sexualidade. In O Corpo Educado: pedagogias da sexualidade. Tradução dos artigos: Tomaz Tadeu da Silva. 2 ed. Belo Horizonte: Autêntica, 2007.

PACHECO, Ana Cláudia L. Mulher negra: afetividade e solidão. Salvador: EDUFBA, 2013.

MAGNANI, José Guilherme Cantor. De perto e de dentro: notas para uma etnografia urbana. Revista Brasileira de Ciências Sociais, v. 17, n. 49, jun. 2002.

MOREIRA, Núbia Regina. A organização das feministas negras no Brasil. Vitória da Conquista: Ed. UESB, 2011.

SANTOS, Maria José dos. Trajetórias educacionais de mulheres quilombolas no Quilombo das Onze Negras no Cabo de Santo Agostinho-PE. Dissertação de Mestrado em Educação: história, política e sociedade. Pontifícia Universidade Católica de São Paulo. 2012.

SARDENBERG, Cecília M. B.; MACEDO, Márcia S. Relações de gênero: uma breve introdução ao tema. (2011). Disponível em: http://pt.scribd.com/doc/52253940/Introducao-agenero-marcia-e-cecilia-revisado. Acesso em: 11.10.2014.

SCOTT, Joan. Gênero: uma categoria útil para análise histórica. Trad.: Christine Rufino Dabat, Maria Betânia Ávila. Texto original: Joan Scott — Gender: a useful category of historical analyses. Gender and the politics of history. New York, Columbia University Press. 1989.

SILVA, Valdélio Santos. Rio das Rãs à luz da noção de quilombo. Revista Afro-Ásia, n. 23, 2000 .

SPIVAK, Gayatri Chakravorty. Pode o subalterno falar? Trad. Sandra R. G. Almeida, Marcos p. Feitosa, André p. Feitosa. Belo Horizonte: Editora UFMG, 2010.

Recebido em 8 de agosto de 2015.

Aceito em 2 de setembro de 2015. 